\title{
Since the eruption of Mt. St. Helens, has anyone beaten you up? Improving the accuracy of retrospective reports with landmark events
}

\author{
ELIZABETH F. LOFTUS and WESLEY MARBURGER \\ University of Washington, Seattle, Washington 98195
}

\begin{abstract}
When people are questioned about past experiences, it is common for events to be reported as happening more recently than they actually did. One technique for reducing the instances of this "forward telescoping" is tested in the current research: It involves the provision of landmark events that can clearly mark the beginning of the reference period. Such a technique was shown to reduce the telescoping problem in five experiments, involving 1,694 subjects. The landmark event used in two of the studies was the first major eruption of Mt. St. Helens, and use of this event was shown to significantly reduce the incidence of forward telescoping of crime victimizations. Asking subjects to provide their own personal landmarks had similar beneficial effects. Finally, a more usual public landmark event, New Year's day, substantially reduced forward telescoping. At least part, but not all, of the benefit of landmark events appears to be due to their being dated rather precisely.
\end{abstract}

"I was brought up in a country vicarage, after all. They date things by events, they don't date them by years. They don't say 'That happened in 1930 ' or 'That happened in 1925 ' or things like that. They say, 'That happened the year after the old mill burned down' or 'That happened after the lightning struck the big oak and killed Farmer James' or 'That was the year we had the polio epidemic.' So naturally, of course, the things they do remember don't go in any particular sequence. Everything's very difficult," she added. "There are just bits poking up here and there...."

-Agatha Christie, 1968 By the Pricking of My Thumbs

Retrospective surveys gather data that rely crucially on the memory of respondents. The task of developing ways of obtaining accurate information about past events, including information about when those events occurred, presents a major challenge to the survey interviewer. When people try to recall particular episodes from their past, whether these are trips to the doctor, legal violations, or instances of crime victimization, at least two kinds of memory errors can and do occur. First, an episode can be completely forgotten. Second, an episode can be recalled but erroneously remembered as having occurred more recently than it did, an error

This research was supported by grants from the National Science Foundation and the National Bureau of Standards. The ideas for these experiments came after the senior author's participation in a workshop sponsored by the Bureau of the Census and the Bureau of Social Science Research. We are grateful to P. Barnard, J. Morton, and E. Tulving for useful discussions of temporal memory, and to A. Biderman for comments on the manuscript. Please address all correspondence to Elizabeth Loftus, Department of Psychology, University of Washington, Seattle, Washington 98195. called "forward telescoping." When a person reports a robbery as having occurred during the previous 6 months and police records show that it took place 8 months ago, a telescoping error has been made.

In the experiments reported here, we have tested a fairly simple technique for improving the accuracy of retrospective accounts; the technique takes advantage of a highly salient landmark event. Although the procedure was developed in the context of data on crime victimization, the general ideas are adaptable to a wide variety of survey domains, including health (Cannell, Oskenberg, \& Converse, 1977), consumer behavior (Blum, 1977; Sudman \& Bradburn, 1973), and recollections from childhood and other early periods of life (Yarrow, Campbell, \& Burton, 1970). The procedures are also relevant to numerous everyday situations in which accurate personal memories are of interest. For example, many medical reports that are filled out by individuals who wish to purchase life insurance ask questions such as "During the past five years have you had dizziness, shortness of breath, pain or pressure in the chest?" (Occidental Life Insurance Company of California) and "During the past two years, have you used barbiturates, sedatives, or tranquilizers except as prescribed by a physician? (Transamerica Life Insurance and Annuity Company).

The National Crime Survey (NCS) is a major statistical series instituted by the Law Enforcement Assistance Administration (LEAA) in 1972 to develop new information on the incidence of crime and its impact on society. Data are collected via personal interviews at 6-month intervals in thousands of households (National Academy of Sciences, 1976). To illustrate, several 
questions on the 1980 survey ask about victimizations that may have occurred in the last 6 months: for example, "Did anyone try to rob you by using force or threatening to harm you?" or "Did anyone beat you up, attack you, or hit you with something, such as a rock or bottle?" In general, information is collected on the circumstances under which the event occurred, the effects on the victim, and whether the incident was reported to the police. A major concern of survey designers is the extent to which survey respondents accurately remember, and accurately report to interviewers, incidents that have happened to them. One problem for interviewers is that victims forget that victimizations have occurred or else deliberately fail to mention a victimization. But an equally important problem is forward telescoping, or a memory distortion in which victimizations that occurred prior to the beginning of the reference period are "telescoped" forward into the reference period. In one study, a check of known victimizations revealed that about $20 \%$ of those that were shown in police records as having occurred prior to the beginning of the reference period were reported by victims as having occurred within the reference period (Garofalo \& Hindelang, 1977). Such forward telescoping obviously inflates the estimated number of victimizations reported as occurring in the reference period. Although there is some evidence that "backward telescoping" may move events into the more distant past, this is not a common error (Sudman \& Bradburn, 1973).

One solution to the problem of forward telescoping is the use of bounded interviews. Briefly, the interviewer is provided a summary of the victimizations reported by the respondent during the interview conducted 6 months prior to the current interview. If the respondent reports a victimization in the current interview that is similar to one reported previously, the interviewer can probe further to determine whether the same event is being reported and, if so, exclude it from the current record. (Bounded interviews were first used successfully by Neter and Waksberg, 1964, in their study of household alterations and repairs.) This solution to the telescoping problem has several disadvantages. First, it obviously cannot be used in cases that are entering the survey panel for the first time. Data from cases that are entering the survey panel for the first time cannot be used to estimate the extent of victimization, but only to provide bounding information for subsequent interviews, and thus the technique is wasteful of data. Furthermore, the interviewer must spend additional time during the second interview cross-checking in order to ascertain whether the same event is being remembered, thus increasing the time needed for the second interview. The bounding control also depends upon being able to complete successive interviews with the same respondent in two waves of a panel design. In the NCS, because of respondent mobility and other reasons for noninterviews, "while 82 percent of all interviews on the average are actually bounded, only two-thirds of all reported crime incidents come from interviews that are actually bounded" (Reiss, Note 1, pp.i-ii). Our purpose in the present research was to explore alternative techniques that would not have these disadvantages.

Our exploration began with the realization that researchers in human memory know very little about how memory keeps track of when an event happened. "Time coding" is an important property of human memory (Morton, 1971), but it has been studied relatively little, and generally in rather pallid situations. A few laboratory studies have been conducted in which a subject is exposed to a long series of items such as words or nonsense syllables, and memory for when these occurred is tested. In some cases, each item appears twice; the two presentations are separated by a controlled number of intervening items, and when the second presentation occurs, the subject must indicate how far back in the series the first presentation was (Hinrichs, 1970). In other studies, subjects are shown two items that have both been presented earlier and must decide which of the two occurred more recently (Yntema \& Trask, 1963). In the first case, the subject makes absolute judgments of recency, whereas in the second case, the subject makes relative judgments. In both cases, the memory strength of items seems to affect judgments of recency in a positive direction; that is, stronger items are judged to be more recent (see also Bower, 1972; Morton, 1968). A related finding is that the recency judgments of accurately recalled items are better than those of inaccurately recalled items (Brelsford, Freund, \& Rundus, 1967).

This item-strength phenomenon may be at the heart of forward telescoping. An experience with crime is for most individuals a highly salient one, an often repeated one, and this may contribute to its apparent recency. Moreover, asking a question such as "In the last 6 months, did anyone try to rob you?" is similar to asking for an absolute judgment. For some individuals, such events may be stored along with a calendar date that is retrieved directly. However, in other cases, the person will reconstruct the approximate date by retrieving some of the surrounding context in which the event was located. By carefully searching memory, he or she may eventually stumble across a memory that is temporally dated (perhaps an important memory), and from this associated information, the time of the to-be-remembered event can be calculated.

The technique used in the present research involved providing respondents with some "surrounding context" in the form of a landmark event that was solidly dated and highly salient to all of them. The event was the first major eruption of Mt. St. Helens, which occurred on May 18,1980, and was well known to residents of the northwestern United States. Since one of the ways that people remember past experiences is through the use of landmarks (Lindsay \& Norman, 1972; Williams, 1976) and since subjects who spontaneously use per- 
sonal landmarks tend to be more accurate in their recollections (Baddeley, 1979), we hypothesized that providing a powerful landmark event might effectively mark the beginning of the reference period and reduce the incidence of forward telescoping. Accordingly, 6 months after the eruption, subjects in two experiments were asked questions of the form, "In the last 6 months, did anyone try to rob you?" or questions of the form "Since the first major eruption of Mt. St. Helens, has anyone tried to rob you?"

\section{EXPERIMENT 1}

\section{Method}

Subjects in Experiment 1 were interviewed on November 17, 18 , and $19,1980,6$ months after the first major eruption of Mt. St. Helens. The subjects included 144 individuals who were (1) ordinary citizens in and around the city of Seattle (November 17), (2) passengers at the Seattle/Tacoma airport who were waiting for Northwest Orient Flight 50 between Seattle and Minneapolis, which left $1 \mathrm{~h}$ late due to fog at an intermediate stop, and passengers on Northwest Orient Flight 76 between Seattle and Chicago, which the experimenter took instead of Flight 50 (November 18), and (3) passengers on United Airlines Flight 145 between Chicago and Portland (November 19). Each subject was asked a series of questions about crime victimization; 76 subjects were asked questions of the form "In the last 6 months, did anyone try to rob you?" and 68 subjects were asked the same question but in the form "Since the first major eruption of Mt. St. Helens, has anyone tried to rob you?" Specifically, subjects were approached individually and asked whether they would participate in a brief survey. If they agreed, they were asked: (1) During the last 6 months, did anyone steal anything that belonged to you? (2) During the last 6 months, did anyone try to rob you by using force, such as by a stick-up, mugging, or threat? (3) During the last 6 months, did anyone beat you up, attack you, or hit you with something such as a rock or bottle?

The remaining subjects were asked the same questions with the phrase "Since the first major eruption of Mt. St. Helens" in place of "During the last 6 months." These subjects were also asked whether or not they knew when the first major eruption of the volcano had occurred.

\section{Results}

A simple count of the number of subjects who reported at least one victimization indicated that, as predicted, reported victimizations were greater when subjects were asked the "6-months" questions than when they were asked the "Mt. St. Helens" questions. Seven subjects $(9.2 \%)$ reported at least one victimization in the former case, compared with one subject $(1.5 \%)$ in the latter case $(\mathrm{z}=2.03, \mathrm{p}<.05)$.

Postinterview probing revealed further evidence in support of the hypothesis that a salient landmark better enables respondents to mark the appropriate reference period. Of the seven individuals who reported at least one victimization in the " 6 -month" condition, two claimed the event had occurred during the summer months and thus was definitely in the 6-month reference period, two said the event occurred prior to the reference period (one of these said it happened just before Easter, itself a landmark event), and three became unsure as to whether the crime occurred before or after the May 18 eruption of the volcano. Put another way, over $28 \%$ of the reported instances of crime from this admittedly small sample were later identified as instances of telescoping. Of the remaining 69 individuals who had been asked the "6-month" question and reported no victimizations, 1 person spontaneously reported a victimization that had occurred very early in the year. Turning to those who had been asked the "Mt. St. Helens" question, four reported that they had been victims earlier in the year, prior to the eruption of Mt. St. Helens. These were crime victimizations that might have potentially been telescoped into the reference period had the question been asked in a different way. All subjects in the Mt. St. Helens condition were asked whether they knew the date of the eruption. All but one individual said the eruption had occurred on May 18, in mid-May, or in the month of May.

In summary, these results suggest that the introduction of a salient landmark event effectively reduces the amount of forward telescoping. The next experiment explores the use of this procedure in a within-subjects design.

\section{EXPERIMENT 2}

\section{Method}

Subjects in Experiment 2 included 82 students at the University of Washington who participated on November 17, 18, and 19 , and an additional 50 subjects who participated on January 18 , 1981 (precisely 8 months after the eruption of the volcano). The November subjects were asked the "6-months" version of each question, whereas the January subjects were asked the same questions with the phrase " 8 months" inserted in place of "6 months."

Each subject was first asked these seven questions. (1) During the last 6 months, did anyone steal things that belonged to you from inside any car or truck, such as packages or clothing? (2) During the last 6 months, were you knifed, shot at, or attacked with some weapon by anyone at all? (3) Did you call the police during the last 6 months to report something that happened to you which you thought was a crime? (4) Did anything happen to you during the last 6 months which you thought was a crime but did not report to the police? (5) Did the failure to rescue the hostages in Iran happen during the last 6 months? (6) Did you have a birthday during the last 6 months? (7) During the last 6 months, have you eaten lobster?

After completing these items, the forms were collected and a new form was distributed. The second form was identical to the first except the phrase "Since Mt. St. Helens erupted ...." replaced the 6- (8-) months phrase. The data were collected in this order only because when the reverse was tried, subjects virtually always gave the same answer the second time as the first, suggesting that reminding them of the eruption may have changed the very nature of the other (landmark-absent) condition.

\section{Results}

The percentage of subjects who responded yes-yes, no-no, yes-no, and no-yes to each of the seven items is given in Table 1. Notice that for each item the proportion of yes-no responses exceeds the proportion of no-yes responses, indicating that it is more likely that 
Table 1

Percentage of Subjects Given Each Combination of Responses (Experiment 2)

\begin{tabular}{lcrrrr}
\hline $\begin{array}{l}\text { Question } \\
\text { Asked* }\end{array}$ & $\mathrm{n}$ & $\mathrm{Y}-\mathrm{Y}$ & $\mathrm{N}-\mathrm{N}$ & $\mathrm{Y}-\mathrm{N}$ & $\mathrm{N}-\mathrm{Y}$ \\
\hline 1. steal? & 129 & 9.3 & 86.0 & 4.7 & 0 \\
2. attack? & 129 & 3.1 & 95.3 & 1.6 & 0 \\
3. report? & 124 & 14.5 & 82.3 & 3.2 & 0 \\
4. no report? & 127 & 18.1 & 79.5 & 2.4 & 0 \\
5. hostages? & 121 & 41.3 & 30.6 & 23.1 & 5.0 \\
6. birthday? & 129 & 51.2 & 40.3 & 7.0 & 1.6 \\
7. lobster? & 128 & 20.3 & 77.3 & 2.3 & 0 \\
\hline
\end{tabular}

Note $-N=$ no; $Y=$ yes.

*Within 6 months?/Since Mt. St. Helens?

subjects later decide that something they thought happened within the 6- (8-) month reference period had not actually happened since the eruption of the volcano than the other way around. The strongest effect occurred with the "hostages" item, on which $23 \%$ of the subjects first indicated the event happened in the reference period but later changed their minds. Only 5\% of the subjects first thought the event had not happened within the reference period and then changed their minds.

The only two items that permit us to assess the accuracy of response are the hostages item and the birthday item. Consider the hostages item. The failed hostage rescue attempt actually occurred a few weeks prior to the 6- (8-) month reference period. Thus, the correct answer to this item is "no," the event did not occur within that period of time. From Table 1, we can see that the correct response, "no," occurred far more often when the landmark question was asked than in the other condition. Thus, for this item, we can definitely say that the landmark question produced more accurate responding.

To assess the accuracy of the birthday item, we asked a sample of 40 individuals to produce their driver's licenses. Only 31 subjects produced a valid license. By comparing the data on the license with their responses, we ascertained that $100 \%$ of the subjects accurately responded to the birthday item when asked the "landmark" question; however, two individuals $(6.5 \%)$ were inaccurate in their response to the birthday item when asked the nonlandmark version of the question. Once again, the analysis of this item leads to the suggestion that not only does the landmark question reduce forward telescoping, but it results in more accurate responding.

\section{EXPERIMENT 3}

In Experiment 2, we found that asking a person first about activities since some landmark event seemed to influence their responses when they were later asked about their activities during a corresponding time interval. We suggested that this occurred because the prior provision of a landmark induced subjects to use this landmark when asked the other version of the question. One suggestion from this result is that it should be possible to ask subjects to provide their own landmark, which they could then use in answering subsequent questions. In Experiment 3, we explored this possibility.

\section{Method}

Subjects in Experiment 3 included 200 students at the University of Washington. Each subject was asked a series of questions about crime victimization. All of the subjects were asked questions of the form "In the last 6 months, did anyone try to rob you?" However, prior to answering these questions, half of the subjects were first asked to think of an important event that happened roughly 6 months earlier and then to provide a date for that event. We refer to these as the "personal landmark" subjects.

Subjects were asked three critical questions, and these were the same as the questions asked of the subjects who participated in Experiment 1. The questions were: (1) During the last 6 months, did anyone steal anything that belonged to you? (2) During the last 6 months, did anyone try to rob you by using force, such as by a stick-up, mugging, or threat? (3) During the last 6 months, did anyone beat you up, attack you, or hit you with something such as a bottle or rock?

\section{Results}

A simple count of the number of subjects who reported at least one victimization indicated that, as predicted, reported victimizations were fewer when subjects were asked to provide a personal landmark than when they were not. Eleven percent reported at least one victimization in the no-landmark case, compared with $2 \%$ in the landmark case.

This result suggests that the introduction of a personal landmark, like a public landmark, similarly reduces the amount of forward telescoping.

\section{EXPERIMENT 4}

The results of Experiments 1 and 2 suggest that questioning subjects about their crime-victimization experiences with reference to a landmark event such as the eruption of Mt. St. Helens leads to fewer instances of forward telescoping. However, it seems likely that this particular event would serve as a landmark event only for a certain segment of the population (e.g., those living in the Pacific northwest) and only for a circumscribed period of time. If so, then the practical value of this particular landmark is rather limited. On the other hand, if a landmark event could be something like an election of a president, Christmas, or New Year's day, then the practical use of the results would be obviously much expanded. For this reason, we conducted Experiment 4 using a more usual event, New Year's day, as the marker.

\section{Method}

Subjects in Experiment 4 included 498 persons who participated on June 30 , July 1 , and July 2,1981 . These were individuals who were contacted at five major shopping areas in and around the Seattle area. A different experimenter conducted 
Table 2

Number of Victimizations Reported at Each of Five Shopping Locations (Experiment 4)

\begin{tabular}{ccc}
\hline \multirow{2}{*}{$\begin{array}{c}\text { Shopping Center } \\
\text { Location }\end{array}$} & \multicolumn{2}{c}{ Question Type } \\
\cline { 2 - 3 } & 6 Months & New Year's Day \\
\hline 1 & 3 & 1 \\
2 & 3 & 1 \\
3 & 4 & 3 \\
4 & 2 & 1 \\
5 & 4 & 2 \\
Total & 16 & 8 \\
\hline
\end{tabular}

the interviews at each shopping area and spoke to approximately 100 persons. Each respondent was asked a series of questions about crime victimizations, with half being asked questions of the form "During the last 6 months, did anyone try to rob you?" and the remainder being asked the same question but in the form "Since New Year's day, has anyone tried to rob you?"

Specifically, subjects were approached individually and asked whether they would participate in a brief survey. If they agreed, they were asked the three questions posed in Experiment 1: one concerning thefts, one concerning robberies, and one concerning assaults.

\section{Results}

A simple count of the number of subjects who reported at least one victimization indicated that, as predicted, reported victimizations were more numerous when subjects were asked the "6-months" questions than when they were asked the "New Year's day" questions. The data can be seen in Table 2. Sixteen victimizations were reported in the former case, and only eight in the latter case. The result held for each of the five locations, rendering the results significant by a sign test over locations.

\section{EXPERIMENT 5}

The previous studies have shown that the simple introduction of a landmark event served to reduce the incidence of errors of temporal judgment. A question arises as to why the provision of landmarks has this beneficial effect. The landmark technique may achieve its power by converting a difficult absolute judgment of recency to an easier relative judgment of recency. Of course, the landmark question may work for other reasons as well. For example, the landmark question may serve to emphasize to the respondent that he or she should pay increased attention to the precise dates of any reported events. "During the last 6 months ...?" may be interpreted as any time in the last 6 months or so; "Since the eruption . . .?" may more strongly suggest that the precise date is crucial. To ascertain whether landmark events play any role beyond their virtue of being dated more or less exactly, Experiment 5 was conducted.

Experiment 5 was similar in many ways to Experiment 4 , with the addition of one important control. On a specific date, we asked people whether they had been victimized either during the past 6 months or since a prior specific date (e.g., December 5) that was precisely 6 months earlier. If phrasing the question in the latter way reduces telescoping as much as the landmark did, then we would conclude that landmark events derive their benefit from being specifically dated.

\section{Method}

Subjects included 720 persons who responded to a telephone interview. Eight experimenters conducted the interviews, and all were blind as to the purpose of the experiment. Each interviewer was assigned a different letter of the alphabet and subsequently called 90 individuals whose names began with the given letter.

The calls were made during the months of June and July 1982. Respondents were told that this was a survey on attitudes toward crime, and they were then asked a series of questions including questions about crime victimizations. One-third were telephoned on June 30 , July 1 , and July 2 and were asked questions of the form "During the last 6 months, did anyone try to rob you?" One-third were called on these same three dates and were asked the same questions but with the form "Since New Year's day, has anyone tried to rob you?" These two groups, then constitute a replication of Experiment 4 . The last one-third of the subjects were telephoned within 2 weeks of the critical 3-day period and were asked "During the last 6 months, that is since last December 16 [or other specific date that was precisely 6 months earlier], has anyone tried to rob you?' Respondents were telephoned only on dates that would refer them to nonsignificant dates 6 months before. For example, no one was telephoned on a day in June that would have referred them to December 25, or Christmas day. More specifically, subjects were queried using one of three question forms, and they were asked three separate questions about crime victimization. The three questions were those posed in Experiments 1 and 4: one concerning thefts, one concerning robberies, and one concerning assaults.

\section{Results}

A simple count of the number of subjects who reported at least one victimization can be seen in Table 3. Twenty persons (8.3\%) reported at least one victimization in the "6-month" condition, whereas eight persons (3.3\%) reported at least one in the "New Year's" condition. This difference was significant by a sign test

Table 3

Number of Victimizations Reported to Each of Eight Interviewers (Experiment 5)

\begin{tabular}{lccc}
\hline & \multicolumn{3}{c}{ Question Type } \\
\cline { 2 - 4 } Interviewer & 6 Months & New Year's & Specific Date \\
\hline 1 & 3 & 1 & 2 \\
2 & 2 & 0 & 1 \\
3 & 4 & 2 & 3 \\
4 & 2 & 1 & 2 \\
5 & 1 & 2 & 2 \\
6 & 3 & 1 & 2 \\
7 & 2 & 0 & 1 \\
8 & 3 & 1 & 2 \\
Total & 20 & 8 & 15 \\
Percent & 8.3 & 3.3 & 6.3 \\
\hline
\end{tabular}


across interviewers and replicates the data from Experiment 4. Of additional interest are the data from the "specific-date" condition. Here there were 15 reported victimization $(6.3 \%)$, a figure that was intermediate between the other two. Sign tests revealed that the "specific-date" subjects reported significantly more victimizations than the "New Year's" subjects, and marginally fewer victimizations than the "6-months" subjects.

\section{GENERAL DISCUSSION}

When people are asked about their experiences as crime victims, they appear to exhibit a distortion of recollection in which the victimization appears to have occurred more recently than it actually did. For example, events that occurred 7,8 , or 9 months ago and earlier are often "recalled" as if they had occurred within a 6-month period or less. It is natural to ask why these experiences seem subjectively to have occurred more recently than they did. One possibility is that these experiences with crime are salient ones that are repeated to friends, relatives, and acquaintances. Their salience, and their repetition, may contribute to their strength in memory and, consequently, to their perceived recency. More recent repetition, then, may underlie the errors in the estimation of when a particular past event occurred. Of course, the current research still leaves open the question of whether forward-telescoping effects will be confined to events like crime or whether they will generalize to other mundane items (e.g., In the last 6 months, have you purchased a new pair of shoes?). If repetition of the crime episodes is at the heart of the telescoping problem, then the effects should be much larger for those sorts of events than for events of a more ordinary nature.

Whatever the mechanism that causes this forward telescoping, be it actual memory distortion or response bias, it is important to explore techniques for minimizing such distortions in reporting. In the current research, we have studied one possible technique, namely the provision of "landmark" events in the course of questioning respondents. In our experiments, the simple introduction of a landmark event served to reduce the reported incidence of victimization. Based upon an analysis of items for which validation data were available, we infer that the provision of landmarks did indeed improve the accuracy of temporal judgments. The landmark technique appeared to have beneficial effects whether it was a public one (e.g., eruption of Mt. St. Helens, New Year's day) or a private one for the subject (e.g., his or her own birthday, start of a new academic quarter). Although the provision of specific dates improved the telescoping problem over and above a simple "within the last 6 months" type question, the landmark questions were superior. Thus, the landmark events appear to play a role in reducing telescoping above and beyond their virtue of being dated more or less exactly.

One of the most serious questions raised by this research is the question of exactly what it is that constitutes a landmark event. Can we create a test to determine whether an event can serve as a landmark event? As an initial step, we might ask subjects to estimate the date of a potential landmark event and assess its accuracy. Landmark events might be defined as those that can be validly dated. In fact, subjects in Experiment 1 were asked if they knew the date of the first major eruption of Mt. St. Helens, and virtually all did. We hardly needed to ask subjects in Experiments 4 and 5 whether they knew the date of New Year's day; it seems evident that they would. However, if landmark events are more than simply precisely dated events, we must have some additional criteria-importance, memorability, or whatever-to classify something as a genuine landmark. Perhaps some personal and national landmark events could be defined as those that change one's life or that diagnose major changes in life-style.

Although our research has shown a potential benefit to using landmark events in questioning people about their past experiences, the potential limits of this technique must be acknowledged. First, landmark events themselves may be telescoped forward in people's memories. Second, an event such as Mt. St. Helens, which is known to all residents of the Pacific northwest, would not serve as an adequate anchor in a nationwide survey. One needs an event that is perfectly anchored among all target population groups, and something like New Year's day, then, becomes more practical. But there are problems that will still arise with the use of events that are usable landmarks. When a survey involves tens of thousands of respondents, the interviews may last over a period of several months. Respondents who are interviewed early and late in the study will be answering for substantially different lengths of time.

In developing specific landmark-type questions to ask respondents in surveys of this type, one must be concerned with the reference period. In the NCS, it has been customary to use the 6-month reference period, but this is, of course, not the only choice that one could make. The forward-telescoping problem may not be constant across reference periods, and thus the designation of an optimal landmark technique might change with changes in the reference period. For example, in one study on household alterations and repairs, the telescoping effect decreased between 1 and 6 months (Neter \& Waksberg, 1964, reanalyzed by Sudman \& Bradburn, 1973). In that study, it is possible that as time passed, more events were forgotten and thus not telescoped forward. In situations such as serious crime victimizations, in which omissions may be less common and telescoping may be the major source of error, telescoping may actually increase over certain ranges of recall. For example, in a 3 -month recall period, events 
that occurred 4 and 5 months earlier might be telescoped forward, whereas for a 6-month recall period, events that occurred 7 and 8 months earlier, as well as those that occurred as long as 1 year or more before, might be telescoped forward, resulting in greater overstatement of victimizations. Different types of landmarks may be optimal in these two settings. In fact, given the negatively accelerated form of forgetting curves, and given the increased error in the dating of the event as the actual age of that event increases, forward telescoping could be predicted to stay constant, increase, or decrease with landmark age, depending on one's specific model of the process. All this indicates the need for further research into the optimality of the landmark approach.

Further research will also be needed for the development of a badly needed theory of the causes of forward telescoping and the cognitive processes by which the landmark event comes into play in the interview processes. We have here a clear case in which there might be nothing so practical as a good theory. If we had a good theory of the causes of forward telescoping, we might be able to apply a simple statistical correction to responses obtained to the "last-6-months" form of question and dispense with the landmark technique altogether. Indeed, statistical analyses of responses obtained to "last-6-months," "last-year," "last 1.5 . years," and "last-2-years" questions and so on might be revealing of both the temporal nature of the underlying distortion and the statistical nature of the needed correction.

Whatever the mechanism by which these variations in question wording achieve their beneficial effects, the practical consequences of these results are numerous. Those who wish to obtain accurate responses regarding the dates of important past events can do so more efficiently by utilizing comparison events that are salient to the respondent.

The Teacher Brothers' Modern-Day Almanac (1980) seems to have been on the right track when it suggested this: "Have you ever thought about how much more sensible life would be if we marked the passage of time not by the calendar, but by the events that are really important to us? Your child could be ten Superbowl Sundays old, or you could proudly announce that you'd just had your sixth drivers' license renewal, or, better yet, you could say you'd eaten your way through thirty strawberry seasons. It's not so odd, really. After all, the American Indians marked off their new years when the snows came, and the Scandinavian peasants did the same thing with the rye and potato harvests. There was even a tribe in Sumatra that counted time by noting the intervals between smallpox epidemics. Our favorite, though, is the ancient Korean system-it's based on the ripening of the cucumber" (p. 76).

\section{REFERENCE NOTE}

1. Reiss, A. J., Jr. Summary for victim reporting of series and nonseries incidents over time (Tech. Rep. 3). New Haven, Conn: Yale University, Analytical Studies in Victimization by Crime, June 1977.

\section{REFERENCES}

BAddeley, A. The limitations of human memory: Implications for the design of retrospective surveys. In $\mathrm{L}$. Moss \& $\mathrm{H}$. Goldstein (Eds.), The recall method in social surveys. London: University of London Institute of Education, 1979.

Blum, M. L. Psychology and consumer affairs. New York: Harper \& Row, 1977.

Bower, G. Stimulus-sampling theory of encoding variability. In A. W. Melton \& E. Martin (Eds.), Coding processes in human memory. Washington, D.C: Winston, 1972.

Brelsford, J., Freund, R., \& Rundus, D. Recency judgments in a short-term memory task. Psychonomic Science, 1967, 8, 247-248.

Cannell, C. F., Oskenberg, L., \& Converse, J. M. Striving for response accuracy: Experiments in new interviewing techniques. Journal of Marketing Research, 1977, 14, 306-315.

Garofalo, J., \& Hindelana, M. J. An introduction to the National Crime Survey. Washington, D.C: U.S. Department of Justice, 1977.

Hinrichs, J. B. A two-process memory strength theory for judgment of recency. Psychological Review, 1970, 77, 223-233.

Lindsay, P. H., \& Norman, D. A. Human information processing: An introduction to psychology. New York: Academic Press, 1972.

Morton, J. Repeated items and decay in memory. Psychonomic Science, 1968, 10, 219-220.

Morton, J. What could possibly be innate? In J. Morton (Ed.), Biological and social aspects of psycholinguistics. London: Logo Press, 1971.

National Academy or Sciences. Surveying crime. Report of the panel for the evaluation of crime surveys. Washington, D.C: Author, 1976.

Neter, J., \& WAKsBera, J. A study of response errors in expenditures data from household interview. Journal of the American Statistical Association, 1964, 59, 18-55.

Sudman, S., \& Bradburn, N. M. Effects of time and memory factors on response in surveys. Journal of the American Statistical Association, 1973, 68, 805-815.

Teacher Brothers' modern-day almanac. Philadelphia: Running Press, 1980.

Williams, M. D. Retrieval from very long-term memory. Unpublished doctoral dissertation, University of California, San Diego, 1976.

Yarrow, M. R., Campbell, J. D., \& Burton, R. V. Recollections of childhood: A study of the retrospective method. Society for Research in Child Development Monographs, 1970, 5, 1-83.

YnTema, D. B., \& Trask, F. P. Recall as a search process. Journal of Verbal Learning and Verbal Behavior, 1963, 2, 65-74.

(Received for publication July 13, 1982; revision accepted September 7, 1982.) 